\title{
FORMULATION AND EVALUATION OF METFORMIN HYDROCHLORIDE MICROPARTICLES BY EMULSION SOLVENT EVAPORATION TECHNIQUE
}

\author{
Hemul V. Patel ${ }^{* 1,}$ Kinjal D. Patel and Naynika K. Patel \\ ${ }^{1}$ Department of Pharmaceutical Chemistry, Ashok \& Rita Patel Institute of Integrated study and Research in Biotechnology and Allied \\ Sciences (ARIBAS), New Vallabh Vidyanagar - 388121, Gujarat, India \\ ${ }^{2}$ Department of Biosciences, Sardar Patel University, Vallabh Vidyanagar - 388120, Gujarat, India
}

*Corresponding author's: E-mail: drhemul16@yahoo.com

\begin{abstract}
Metformin $\mathrm{HCl}-$ loaded microparticles of ethyl cellulose were prepared by the emulsion solvent evaporation technique. The aim of this work was to investigate the influence of process variation in polymer type via viscosity grades of ethyl cellulose E1and E10 and drug to polymer ratio on the micromeritic properties. Microparticles evaluated for various characteristic properties such as encapsulation efficiency, particle size \& size distribution, surface morphology and drug release pattern. The optimized formulation parameters were used to prepare porous, spherical micro particles (67 $\mu \mathrm{m}$ to $127 \mu \mathrm{m})$ with high encapsulation efficiency (93 to 97\%). Drug release over a period of $12 \mathrm{hrs}$ ranged from $85.7 \%$ to $98.3 \%$. Microspheres were more spherical in shape in their manufacture with ethyl cellulose E10 and higher ratio of both polymers. Thus, in the case of ethyl cellulose, the viscosity and ratio of the polymer in dispersion medium were found to be the controlling factors of drug release.
\end{abstract}

Key words: Metformin, Ethyl cellulose, micro particles, sustained release, encapsulation efficiency.

\section{INTRODUCTION}

Advances over the last decade in site-specific and/or controlled drug delivery systems are contributing to new and/or improved drug therapies. Drug delivery is becoming an increasingly important aspect in new product research and development in the pharmaceutical industry ${ }^{1}$. Microencapsulation is one of the techniques used to prepare microparticles based sustained release formulation. The techniques of microencapsulation employing various polymers and their applications are described in standard text books. They are widely used techniques to achieve sustained, oral \& parenteral controlled release products and for drug targeting $2-4$ Microspheres are one of the multi particulate drug delivery systems and are prepared to obtain prolonged (or) controlled drug delivery, to improve bioavailability or stability and to target drug to specific sites. Microspheres can be defined as solid, approximately spherical particles ranging from 1 to $1000 \mu \mathrm{m}$, containing dispersed drug in either solution (or) microcrystalline form ${ }^{5,6}$. Ethyl cellulose is non-biodegradable, biocompatible, non-toxic natural polymer and widely used in oral and topical formulation ${ }^{7}$. The microspheres can be produced by several methods utilizing emulsion system (o/w, w/o, o/w/o and w/o/w). The common emulsion system used oil-in-water $(\mathrm{o} / \mathrm{w})$, with microspheres being produced by the emulsion solvent evaporation method. This relatively simple method enables the entrapment of a wide range of hydrophobic drugs ${ }^{8}$. The main object of present study was to investigate the possibility of obtaining sustained release aspirin microsphere by using different concentration of ethyl cellulose, different composition of solvent mixture, different concentration of emulsifying agent and different stirring rate. Aspirin used as a model drug for the present investigation.

Metformin $\mathrm{HCl}$ is a biguanide antihyperglycemic drug, which is orally used in the management of noninsulin- dependent diabetes mellitus (NIDDM or Type II diabetes mellitus) alone or in combination with other hypoglycemic ${ }^{9,10}$. Its antihyperglycemic effect is due to the metabolic activities at several sites (biophase), including liver, intestinal muscle cells, and adipocytes ${ }^{11}$. Metformin also has beneficial effect on several cardiovascular risk factors such as dyslipidemia, elevated plasma-plasminogen activator inhibitor, other fibrinolytic abnormalities and insulin resistance ${ }^{12}$. It has a short biological half-life of $1.5-1.6 \mathrm{~h}$ and the daily requirement of it is $1.5-3 \mathrm{~g} /$ day 13,14 . Therefore, the marketed immediate release product needs to be administered 2- 3 times daily to maintain effective plasma concentration ${ }^{15}$. Henceforth, there being high incidence of gastrointestinal side effects and toxicity. These drawbacks can be overcome by designing suitable sustained release Metformin $\mathrm{HCl}$ formulations. Administration of a sustained Metformin $\mathrm{HCl}$ release dosage form could reduce the dosing frequency and improve the patient compliance. In this present study an attempt is made to prepare Metformin $\mathrm{HCl}$ ethyl cellulose micro particles by emulsion solvent evaporation technique using ethyl cellulose as a carrier to extend the period of drug release by retarding the release rate. The prepared microparticles were evaluated for drug entrapment efficiency, various micromeritic properties, surface morphology and in-vitro drug release pattern.

\section{MATERIALS AND METHODS}

\section{Materials}

Metformin $\mathrm{HCl}$ was a gift sample from Abhilasha Pharma Pvt Ltd, Ankleshwar, Gujarat, India. Ethyl cellulose,EC1,(18-22 cps) Ethyl cellulose (40-42 cps), Sigma Aldrich Pvt. Ltd., USA), Span 80 (Himedia Chemicals Ltd., India), Dichloromethane (International Chemicals, India), (Merck Specialties Pvt. Ltd., India), potassium 
dihydrogen orthophosphate (Himedia Chemicals, India), were used. All other chemicals were of analytical grade and were used as procured.

\section{Methods}

\section{Preparation of microparticles}

Emulsion-solvent-evaporation technique with some modifications was used to prepare ethyl cellulose microparticles containing Metformin $\mathrm{HCl}$ Briefly Metformin $\mathrm{HCl}$ was dissolved in $5 \mathrm{ml}$ distilled water ethyl cellulose was dissolved in Dichloromethane at various drug - polymer ratios (1:2, 1:4 and 1:6). Then these drug and polymer solutions were mixed and emulsified using a Remi Lab Magnetic stirrer (type-RQg$128 \mathrm{~A})$ at $2000 \mathrm{rpm}$ for about $10 \mathrm{~min}$ to form stable w/o emulsion. This stable w/o emulsion was slowly added to $200 \mathrm{ml}$ aqueous solution containing $1 \%$ PVA and stirred at $800 \mathrm{rpm}$ by a mechanical stirrer equipped with a three bladed propeller (Remi motors, India) at room temperature for $2 \mathrm{~h}$ to allow the solvent to evaporate completely. Microspheres were isolated by filtration and washed with distilled water several time to remove PVA. The produced microspheres were dried at ambient temperature $\left(25^{\circ} \mathrm{C}\right)$ for $24 \mathrm{~h}$ and dried in vacuum chamber at $25^{\circ} \mathrm{C}$ for $2 \mathrm{~h}$ to remove any residual solvent. Ethyl cellulose microparticles containing Metformin $\mathrm{HCl}$ with their experimental formulation variables settings are presented in Table 1 .

Table1: Formulation parameters of prepared Metformin HCl-loaded ethyl cellulose microparticles.

\begin{tabular}{|c|c|c|c|}
\hline Formulation & Polymer & Drug to Polymer Ratio & Stirring rate (rpm) \\
\hline F1 & EC1 & $1: 2$ & 800 \\
\hline F2 & EC1 & $1: 4$ & 800 \\
\hline F3 & EC1 & $1: 6$ & 800 \\
\hline F4 & EC10 & $1: 2$ & 800 \\
\hline F5 & EC10 & $1: 4$ & 800 \\
\hline F6 & EC10 & $1: 6$ & 800 \\
\hline
\end{tabular}

\section{Characterization of Microspheres}

\section{Percentage Drug Loading}

Metformin content in the microspheres was estimated by UV Spectrophotometer based on the measurement of absorbance at $206 \mathrm{~nm}$ Microspheres equivalent to $100 \mathrm{mg}$ were weighed and added in $100 \mathrm{ml}$ of $0.1 \mathrm{~N} \mathrm{HCl}$ which was dissolved in a volumetric flask. The volume was made up to $100 \mathrm{ml}$ with $0.1 \mathrm{~N}$ of $\mathrm{HCl}$. The sample was withdrawn, diluted suitably and measured spectrophotometrically at $206 \mathrm{~nm}$ for the drug content. It was performed in triplicates. The percentage of drug loading in microspheres was estimated using the formula below:

$$
\% \text { Drug loading }=\left(\frac{\text { Weight of drug in microspheres }}{\text { Weight of microspheres }}\right) \times 100
$$

\section{Encapsulation Efficiency}

The entrapment efficiency of the prepared microspheres was calculated by the formula:

$\%$ Encapsulation efficiency $=\left(\frac{\% \text { Drug loading }}{\% \text { Theoretical loading }}\right) \times 100$

\section{Scanning electron microscopy (SEM)}

Shape and surface characteristics of the Metformin $\mathrm{HCl}$ loaded microspheres were investigated and photographed using scanning electron microscopy (SEM, JEOL JSM840A). The samples were mounted on an aluminum stage using adhesive carbon type and placed in a low humidity chamber for $12 \mathrm{~h}$ prior to analysis. Samples were coated with gold-palladium for $60 \mathrm{sec}$ under an argon atmosphere using sputter coater in a high vacuum evaporator equipped with an omnirotary stage tray. Images (figure1.A and B) were taken at an acceleration voltage of $20 \mathrm{kV}$ and magnifies of 33- 150 .
(A)

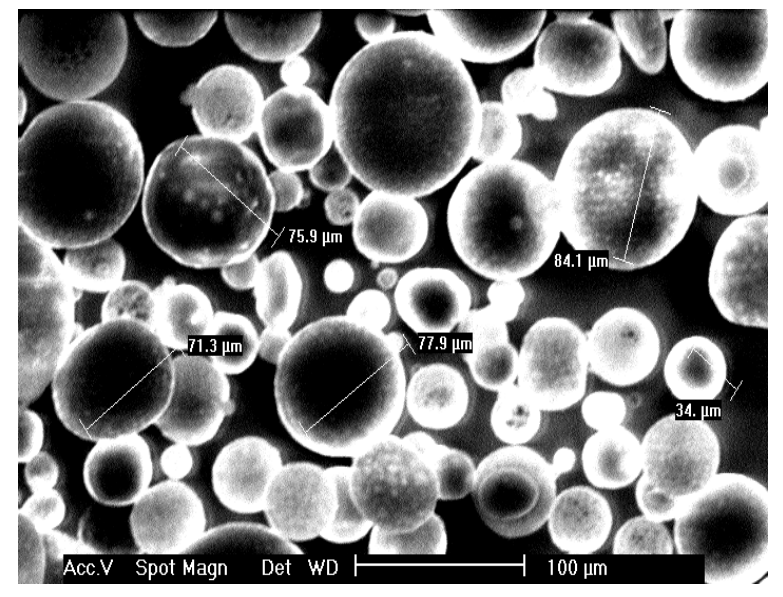

(B)

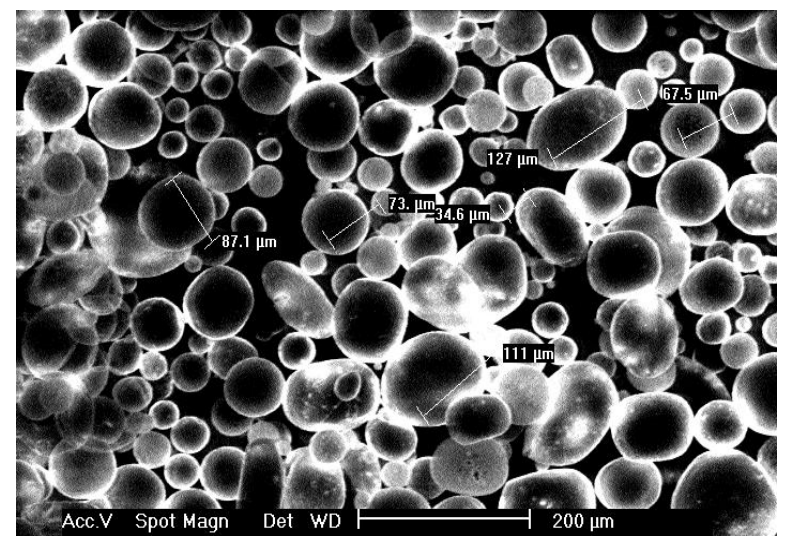

Figure 1: SEM photographs of drug loaded microparticles A. (EC1), B. (EC10). 


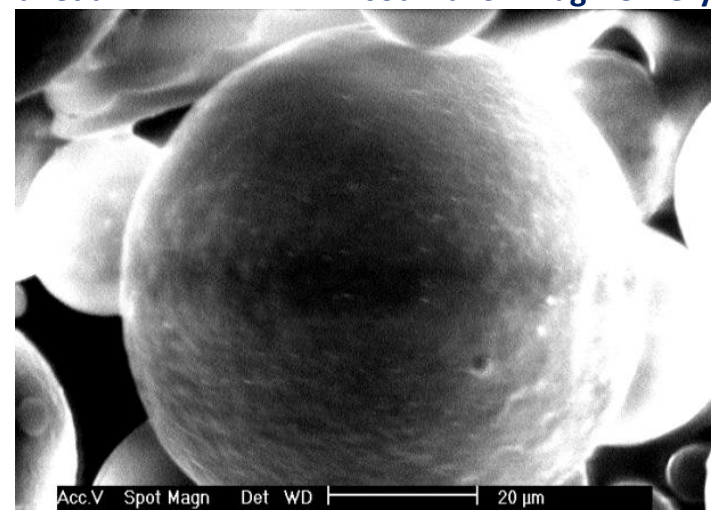

Figure 2: SEM photographs surface of drug loaded microparticles.

\section{X-ray diffraction}

The crystalline nature of drug and drug loaded microparticles was evaluated by powder XRD technique using Philips model "X" Pert, diffractometer attached to the digital graphical assembly and a computer with $\mathrm{Cu}$ target $\mathrm{X}$ ray tube- 4 as $\mathrm{Cu} \alpha$-radiation source in the range of $-3^{\circ}$ to $136^{\circ}$ of $2 \theta$. X-Ray powder Diffraction analysis is a powerful method by which X-Rays of a known wavelength are passed through a sample to be identified in order to identify the crystal structure. The wave nature of the XRays means that they are diffracted by the lattice of the crystal to give a unique pattern of peaks of 'reflections' at differing angles and of different intensity, just as light can be diffracted by a grating of suitably spaced lines. The diffracted beams from atoms in successive planes cancel unless they are in phase, and the condition for this is given by the BRAGG relationship.

$$
\mathrm{nI}=\mathbf{2} \mathrm{d} \operatorname{Sin} \theta
$$

Where,

$\mathbf{l}$ is the wavelength of the X-Rays

$\mathbf{d}$ is the distance between different plane of atoms in the crystal lattice.

$\boldsymbol{\theta}$ is the angle of diffraction.

The X-Ray detector moves around the sample and measures the intensity of these peaks and the position of these peaks [diffraction angle $2 \theta$ ]. The highest peak is defined as the $100 \% *$ peak and the intensity of all the other peaks are measured as a percentage of the $100 \%$ peak.

(A)

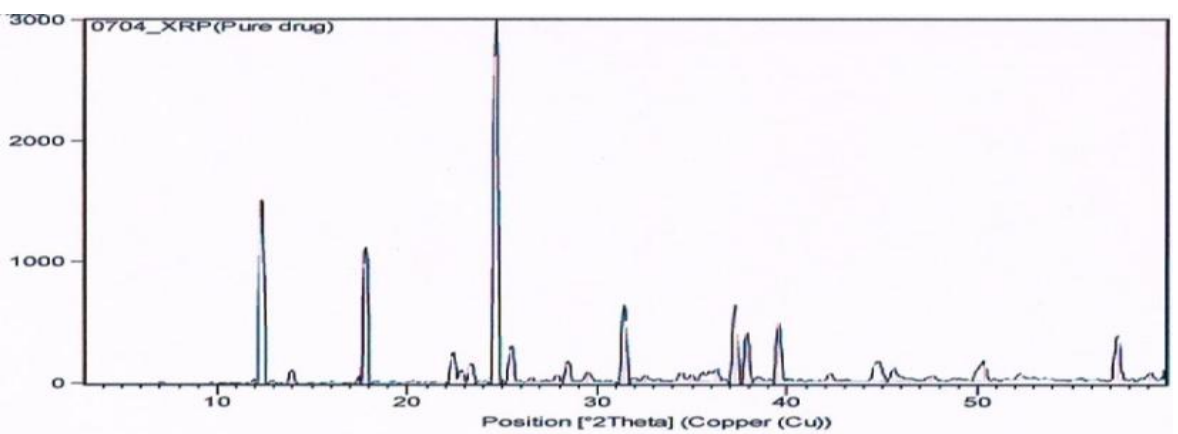

(B)

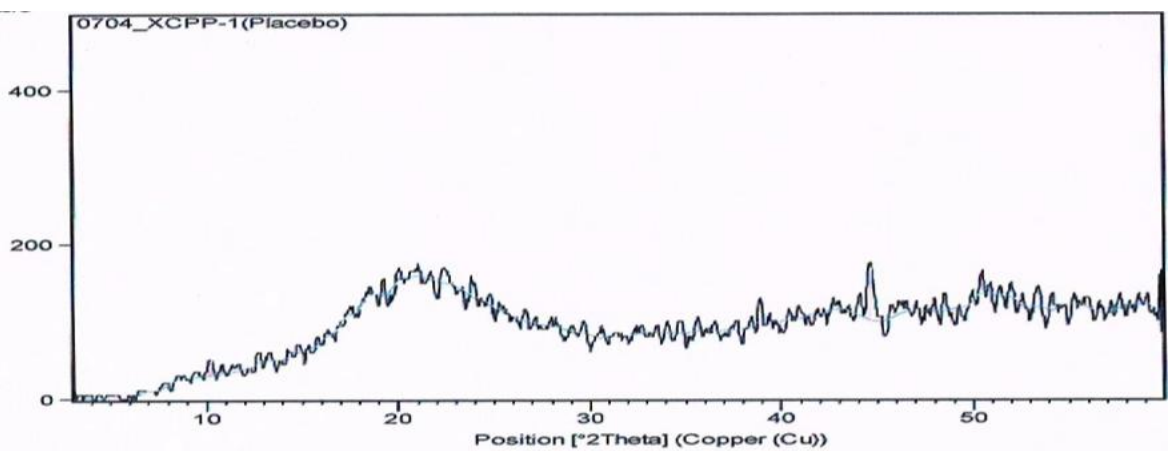

(C)

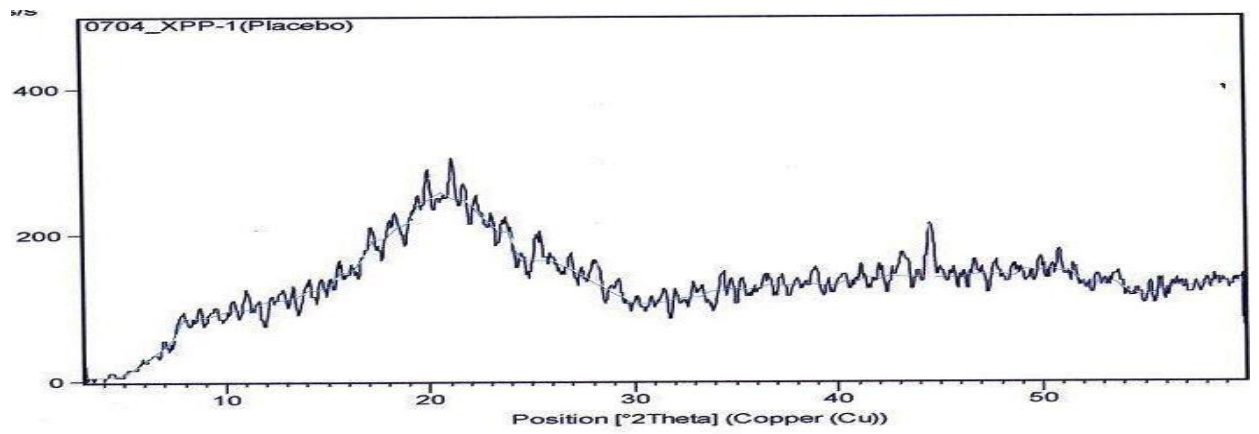

Figure 3: X-ray diffraction of (A) Metformin HCl (b) Ethyl cellulose (C) EC + Drug. 


\section{In-vitro Drug Release Studies}

The percentage of drug (Metformin $\mathrm{HCl}$ ) released from ethyl cellulose microparticles were evaluated in $0.1 \mathrm{~N} \mathrm{HCl}$, $\mathrm{pH} 1.2$ and phosphate buffer, $\mathrm{pH}$ 6.8. The sustained release characteristic of these microparticles was more prominent in $\mathrm{pH} 6.8$ than $\mathrm{pH}$ 1.2.The collected aliquots were filtered and suitably diluted to determine the absorbance using a UV-VIS spectrophotometer (Shimadzu, Japan) at 233nm for phosphate buffer, $\mathrm{pH} 6.8$ and $206 \mathrm{~nm}$ for $0.1 \mathrm{NHCl}, \mathrm{pH}$ 1.2. The release of Metformin $\mathrm{HCl}$ from formulations is shown in figure. 4 and figure.5.

\section{RESULT AND DISCUSSION}

In this study, attempts have been made to develop and formulate Ethyl cellulose coated microspheres by solvent displacement technique at various drug - polymer ratios (1:2, 1:4 and 1:6) using two different grade of ethyl cellulose. Metformin $\mathrm{HCl}$ was used as a model drug to check the drug entrapment efficiency and drug release study. The prepared microparticles were evaluated to check the effect of key parameter affecting on the properties of microparticles. The formulations in Table 1 were prepared in which the increasing amounts of ethyl cellulose either E1 or E10 types were added to the fixed weight of Metformin $\mathrm{HCl}$ with constant stirring rate.. Optimization and proper control of all these variables were essential for the formation of discrete and spherical microspheres. The higher the viscosity and concentration of the selected polymer, the more spherical in shape microspheres can be obtained with lesser micropores on the surface. The SEM micrographs and typical surface morphology of the microspheres is shown in Figure 2. For this reason, F6 microspheres prepared with the highest amount of ethyl cellulose E10 have more regular particles. Microspheres presented a narrow distribution of particle size and generally fallen into the $67 \mu \mathrm{m}$ to $127 \mu \mathrm{m}$ range. Type of ethyl cellulose and its added amount in formulations had a major effect on the viscosity, influencing the particle size distributions. The viscosity of the organic phase due to the concentration of polymer inside was effective on solvent diffusion and emulsification, while the shearing rate during stirring was kept constant. The geometric mean diameters of microspheres were found to be dependent on polymer concentration dispersed in the organic phase.

XRD study of samples (Figure 3A-3C) shows that the drug Metformin $\mathrm{HCl}$ has a crystalline nature Placebo of ethyl cellulose amorphous nature (fig.2B). And the drug loaded particles shows the intermediate nature of crystalline drug and amorphous polymer which clearly indicates dispersion of drugs at molecular level in the formulation and also intensity of XRD was dependent on particle size and its distribution. XRD studies are most important tool for defining nature of any particles.

There is no any interaction between Metformin $\mathrm{HCl}$ and ethyl cellulose during the evaporation process and microsphere formation as indicated in Table 2. The drug loading was affected by neither polymer content nor stirring rate variables, but was consistently and slightly lower than the theoretical loading, with high encapsulation efficiencies close to $100 \%$ in all cases. Also the recovered amount of total microspheres demonstrated the adequacy of process variables during solvent evaporation.

Table 2: Drug loading capacity (Metformin $\mathrm{HCl}$ content), encapsulation efficiency and percent yield of prepared Metformin HCl-loaded microspheres.

\begin{tabular}{|c|c|c|c|c|}
\hline Formulation & $\begin{array}{c}\text { Theoretical } \\
\text { Metformin HCl } \\
\text { Content a (\%) }\end{array}$ & $\begin{array}{c}\text { Measured } \\
\text { Metformin HCl } \\
\text { Content b(\%) } \mathbf{H S . D . 1}\end{array}$ & $\begin{array}{c}\text { Encapsulation } \\
\text { efficiency } \\
\text { (b/a x100) }\end{array}$ & $\begin{array}{c}\text { Yield (\%) } \\
\mathbf{\pm S . D . 1}\end{array}$ \\
\hline F1 & 33.20 & $31.54 \pm 1.20$ & 95.00 & $80.13 \pm 0.33$ \\
\hline F2 & 33.20 & $31.05 \pm 0.96$ & 93.52 & $88.34 \pm 0.15$ \\
\hline F3 & 27.00 & $25.49 \pm 0.14$ & 94.40 & $86.78 \pm 0.74$ \\
\hline F4 & 27.00 & $25.86 \pm 0.32$ & 95.77 & $86.41 \pm 0.86$ \\
\hline F5 & 22.00 & $21.19 \pm 0.66$ & 96.31 & $92.16 \pm 0.67$ \\
\hline F6 & 22.00 & $21.41 \pm 0.29$ & 97.31 & $80.79 \pm 0.11$ \\
\hline
\end{tabular}

The ultimate aim of this present work was to develop sustained release drug delivery system of Metformin $\mathrm{HCl}$. It is observed from the dissolution study that concentration of ethyl cellulose offers sustained effect of the drug up to12hrs. With increasing polymer amount and viscosity, the initial burst effect was significantly decreased in addition to the decrease in second drug release phase. The subsequent decreasing related to drug release rates can be attributed to the resulting decreased drug concentration gradients. In vitro drug release strongly depended on the type of polymer. This might be explained by the higher viscosity of the organic phase in the case of ethyl cellulose. It has been reported that the release of the drug depends on viscosity grade of the ethyl cellulose. With an increasing viscosity grade, the rate of release decreases. It has also been described that, in addition, the release rate depends on the overall viscosity of the system. The present study was able to confirm these findings; for F6 microsphere formations (1:6 drug to polymer ethyl cellulose E10), which had the highest overall viscosity, the slowest release was observed. 


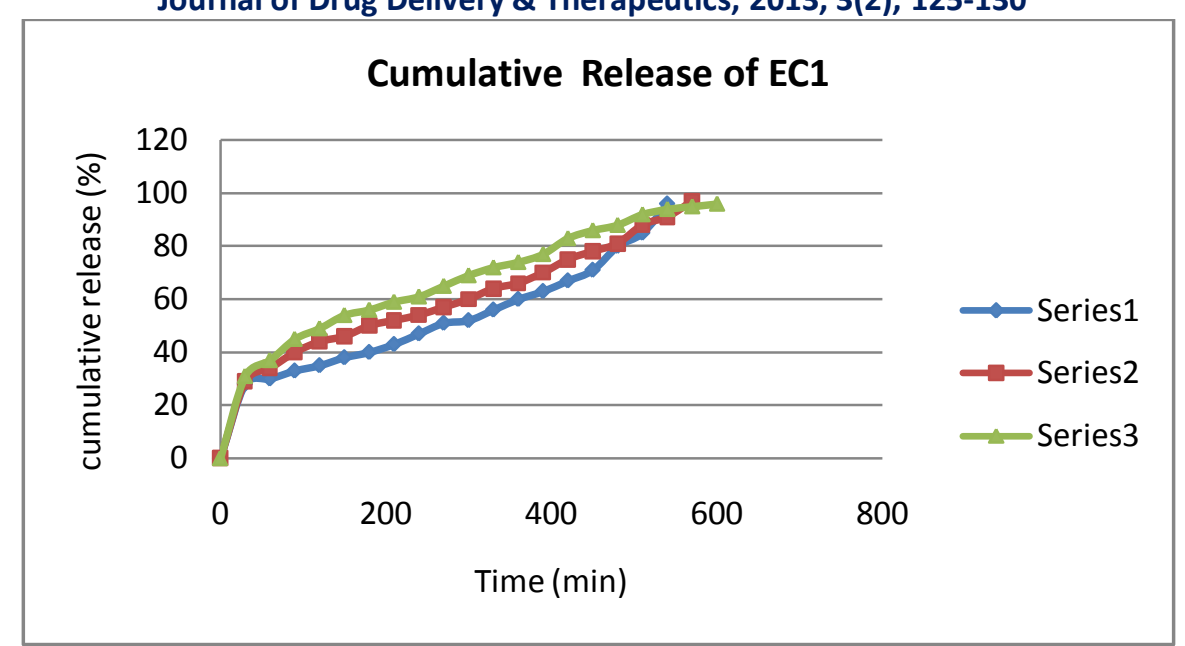

Figure 4: Effect of different drug-polymer ratio (1:2, 1: 4, and 1: 6) on the drug release of (EC1). Series1 (1:2 EC1), series $2(1: 4-E C 1)$ and series $3(1: 6-$ EC1)

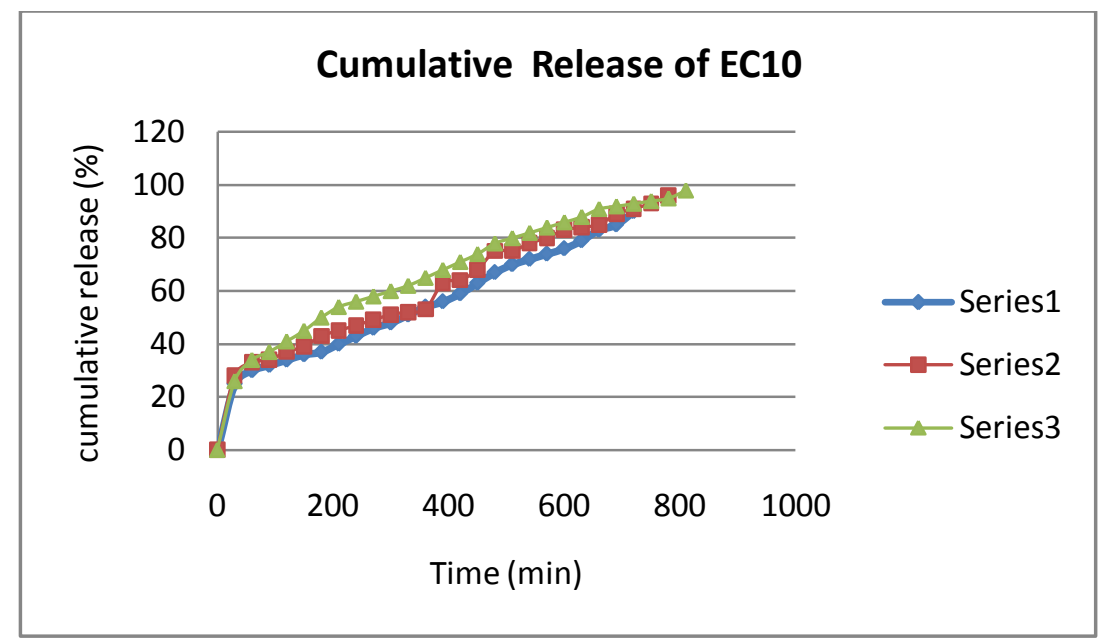

Figure 5: Effect of different drug-polymer ratio (1: 2, 1: 4, and 1: 6) on the drug release of (EC10). Series1 (1:2EC10), series 2 (1:4-EC10) and series 3 (1:6-EC10)

\section{CONCLUSION}

The Metformin $\mathrm{HCl}$ microparticles were prepared successfully by solvent evaporation technique. This study showed that during manufacture of the microspheres by solvent evaporation method, the viscosity and ratio of polymer in dispersion medium were the controlling factors of microsphere micromeritic parameters [16] and drug release. Microparticles prepared using ethyl cellulose was found to be spherical, discrete and free-flowing. High encapsulation efficiency can be attributed to the probability for the drug to be entrapped within the microparticles when increasing the amount of ethyl cellulose.

\section{ACKNOWLEDGEMENT}

The authors would like to thank Abhilasha Pharma Pvt. Ltd, Ankleshwar, Gujarat, (India) for providing gift sample of Metformin hydrochloride. The authors also thankful to Dr. C.L. Patel, Chairman, Charutar Vidya Mandal (CVM) Vallabh Vidyanagar, Gujarat, India for providing facilities during research. Also the facilities for analysis provided by Sophisticated Instrumentation Center for Applied Research \& Testing (SICART), Vallabh Vidyanagar, Gujarat, India for during this research work is greatly acknowledged. 
1. Anal AK. Time-controlled Pulsate delivery systems for bioactive compounds. Recent Patents on Drug Delivery and Formulations, 2007; 1:73-79.

2. Gutcho $\mathrm{MH}$, editor 1976,Microencapsules \&Microencapsulation Techniques, New Jersey Noyes Data corporation P 236.

3. Kondo, Preparation and Permeability characteristics of microcapsule membranes, Journal of Controlled Release, 1990, $11(1-3): 215-224$.

4. Leung SS and Robinson IR, Controlled drug delivery fundamentals and applications, 2nd Ed. New York: Marcel Decker Inc. 1987, p 448

5. Ainley Wade \& Paul J. Weller, Handbook of Pharmaceutical Excipients, 2nd edition, The Pharmaceutical Press, London, 1994, pp 186-190.

6. Das MK and Rao KR. Evaluation of zidovudine encapsulated ethyl cellulose microspheres prepared by water in oil in oil (w/o/o) double emulsion solvent diffusion technique. Acta Pol Pharm, 2006, 63(2), 141-148.

7. Gibaud S, Bonneville A, Astier A. Preparation of 3, 4diaminopyridine microparticles by solvent-evaporation methods. International Journal of Pharmaceutics, 2002, 242:197-201.

8. Hitesh K, Koshy MK, Shubhini AS. Gastroretentive Ethyl Cellulose Floating Microspheres containing Ranitidine Hydrochloride. International Journal of Drug Delivery \& Research, 4(2); 315-321.

9. Stepensky D, Friedman M, Raz I, and Hoffman A, Pharmacokinetic- pharmacodynamic analysis of the glucoselowering effect of metformin in diabetic rats reveals first-pass pharmacodynamic effect, Drug Metabolism and Disposition, 2002,(30)8, 861-868.

10. Block LC, Schemling LO, Couto AG, Mourao SC, and Bresolin TMB, Pharmaceutical equivalence of metformin tablets with various binders, Journal of Applied Pharmaceutical Science, 2008, 29(1), 29-35,

11. Sharma VK and Bhattacharya A, Release of metformin hydrochloride from Ispaghula-sodium alginate beads adhered on cock intestinal mucosa, Indian Journal of Pharmaceutical Education and Research, 2008,42( 4), 363-370,.

12. Dunn CJ, and Peters DH, Metformin: a review of its pharmacological properties and therapeutic use in non-insulindependent diabetes mellitus, Drugs, 1995, 49(5),721-749,

13. Kshirsagar RV, Jain V, and Wattamwar S, Effect of different viscosity grade HPMC polymers on gastroretentive drug delivery of metformin $\mathrm{HCl}$, International Journal of Applied Pharmaceutics, 2009, 1, 44-50.

14. Nath B, Nath LK, Mazumdar B, Sharma NK, and Sarkar MK, Preparation and in vitro evaluation of gastric floating microcapsules of metformin $\mathrm{HCl}$, Indian Journal of Pharmaceutical Education and Research, 2009,43,177-186.

15. Setter Sm, Iltz JL, Thams J, and. Campbell RK, Metformin hydrochloride in the treatment of type 2 diabetes mellitus: a clinical review with a focus on dual therapy, Clinical Therapeutics, 2003,25(12), 2991-3026.

16. Zessin G, Dashevsky A., The effect of viscosity on micromeritic properties of ethyl cellulose-walled theophylline microspheres. 1995 Proc. 1st World Meeting APGI/APV, Budapest, pp. 443444, May 9-11. 